\title{
Reading Errors in Sundials with Incorrect Hour Lines: The Seventeenth-Century Sundial in Lerma
}

\author{
Martín Perea-Álvarez de Eulate ${ }^{1}$ (D) \\ Gloria Del Río-Cidoncha ${ }^{2}$ - Francisco Montes-Tubío ${ }^{1}$
}

\begin{abstract}
The restoration project of a seventeenth century sundial at Lerma (Spain) with incorrect engraved marks for the hour lines and devoid of its gnomon raised the issue of whether it is possible to predict what might be the reading errors when providing a new gnomon for it. Moreover, the analysis of possible slight changes in gnomon's orientation and/or geometrical features to get better precisions was an appealing challenge. We must consider that Lerma's case is not unique: templates were used in the past to engrave marks in numerous dials, and small differences in orientation were not taken into account. Differences in latitude under $0.5^{\circ}$ were also neglected, by rounding off to integer values. Although Lerma's sundial has been our guiding thread and its results are presented in detail, the method can be extrapolated to calculate reading errors for any dials with wrong marks for orientation or latitude different form the actual ones.
\end{abstract}

Keywords Sundials · Gnomons · Solar hours

Electronic supplementary material The online version of this article (https://doi.org/10.1007/s00004018-0387-7) contains supplementary material, which is available to authorized users.

Martín Perea-Álvarez de Eulate

mperalv@ciccp.es

Gloria Del Río-Cidoncha

cidoncha@us.es

Francisco Montes-Tubío

ir1motuf@uco.es

1 Ingeniería Gráfica y Geomática, Escuela Técnica Superior de Ingeniería Agronómica y de Montes, Universidad de Córdoba, Edif. Gregor Mendel C 5, Campus de Rabanales, 14071 Córdoba, Spain

2 Ingeniería Gráfica, Escuela Técnica Superior de Ingeniería, Universidad de Sevilla, Camino de los Descubrimientos s/n, 41092 Seville, Spain 


\section{Introduction}

The sundial located on the main façade of Colegiata de San Pedro, Lerma, Spain (Figs. 1, 2 and 3), is currently devoid of its gnomon and a restoration project is currently being considered for it. Its hour and half-hour lines are engraved in a limestone dial placed on a buttress. A vertical slit in the line of the XII hour suggests that the original caster was a triangular plate, perpendicular to the dial. However, remnants of mortar indicate that a shoddy repair with a steel bar and a supporting stick was attempted in the nineteenth or twentieth century. The analysis of the engraved hour lines indicates that the dial is correctly marked for its latitude and for a wall perfectly oriented southwards (Figs. 3 and 4). However, the southern façade, though perfectly vertical (not inclined ${ }^{1}$ ), is rotated $6.6^{\circ}$ westwards. The angle between the direction vector of the dial's plane and the South direction, called the wall declination, $\delta_{w}$ (Fig. 5), is taken conventionally as positive measured from the South eastwards (Soler 1997), so we have, $\delta_{w}=-6.6^{\circ}$. Therefore, its marks should have been those of Fig. 6. ${ }^{2}$ This geometrical issue will lead to reading errors when a new gnomon is placed, so it is convenient to quantify them. These kinds of error in the marks were not infrequent in sundials on walls slightly rotated from South: templates and pre-calculated tables for dials facing exactly South were often used, and fractions of degrees of latitude were not taken into account. In the case of Lerma's dial, however, only the orientation is wrong: the difference between $42^{\circ}$, the latitude considered, and $42.03^{\circ}$, the actual latitude, is absolutely negligible.

It is not only reading errors that must be calculated for a gnomon presumably similar to the original historic one: with the help of an imaginary group of correct marks, slightly different suitable orientations and angular values for the new gnomon will be tested in order to minimize, if possible, the magnitude of errors. Therefore, the procedure developed in this paper will be useful not only for Lerma's sundial but also for any vertical sundial with mistaken hour lines. First of all, we'll analyse as an example the intervals of the day in which Lerma's dial is operative. Next, we'll develop the geometrical derivations to check different choices for its gnomon, showing the results both numerically and graphically according to the different calculation options. Finally, extrapolation to predict errors in all vertical sundials with problems of orientation or latitude will be stated. Errors in inclined sundials will not be analysed.

\section{Time Intervals in Which the Dial is Operational}

Analysing the time intervals when a sundial receives the Sun rays directly throughout the year will allow us to limit the study of errors to those hours in which it is operational in order to prevent obtaining nonsensical numerical solutions.

\footnotetext{
1 An inclined sundial is also known as reclined. These terms are used for dials located in walls contained in a plane that is not perfectly vertical.

2 Theoretical hour lines graph can be easily obtained from available applications such as "Shadows" (Blateyron 2017), “Orologi Solari” (Casalegno 2017), etc.
} 


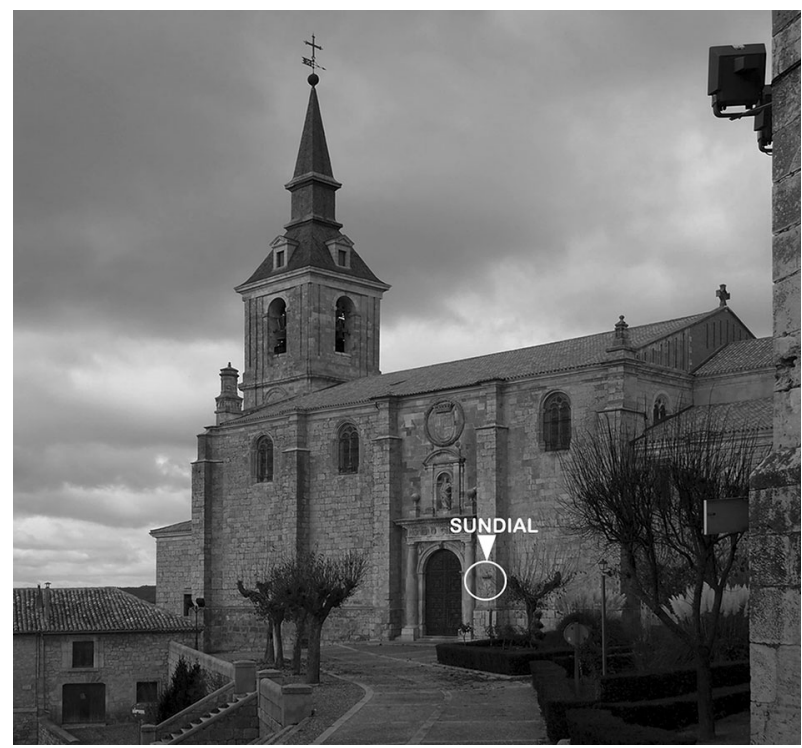

Fig. 1 The Colegiata de Lerma and the position of the sundial

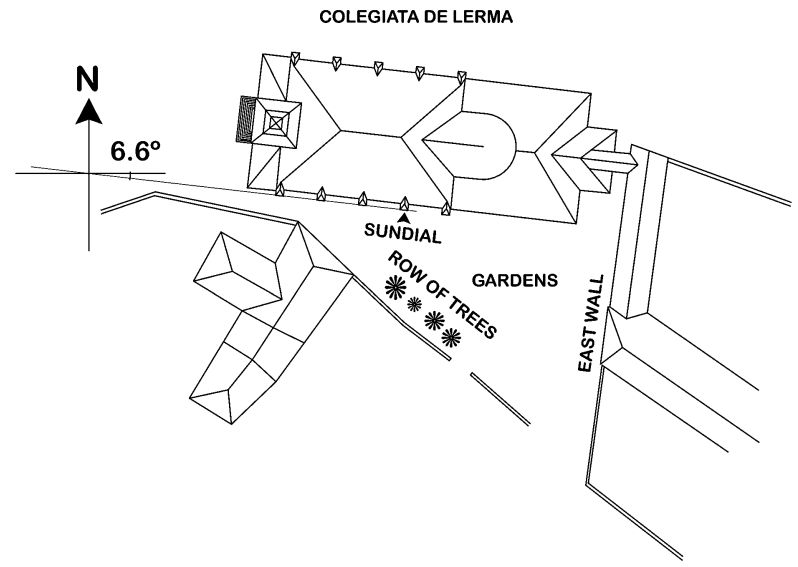

Fig. 2 The sundial's location Image: Authors, after (Cervera Vera 1981) and (SIGPAC 2017)

Lerma's sundial will be our guiding thread. Of course, as Albert Waugh says, "no vertical sundial can ever catch the sun's rays for more than 12 of the $24 \mathrm{~h}$ in a day" (1973, p. 83). Our first input data will be $\delta_{w}$ and the latitude $\varphi$ of an observer located exactly at the same point that the dial. This point is called V in Fig. 7. It must be remarked that all the calculations will be made for local solar time, without any corrections due to equation of time or to daylight saving time. It makes no sense for the aim of this paper to make any comparisons with the hours we can read in our wristwatches. 
Fig. 3 The existing dial, without gnomon. Remnants of an attempt of repair can be seen

Fig. 4 Theoretical hour lines for $\varphi=42.03^{\circ}$, wall facing South $\left(\delta_{w}=0^{\circ}\right)$

Fig. 5 Definition of the wall declination, $\delta_{w}$, as commonly accepted in gnomonics
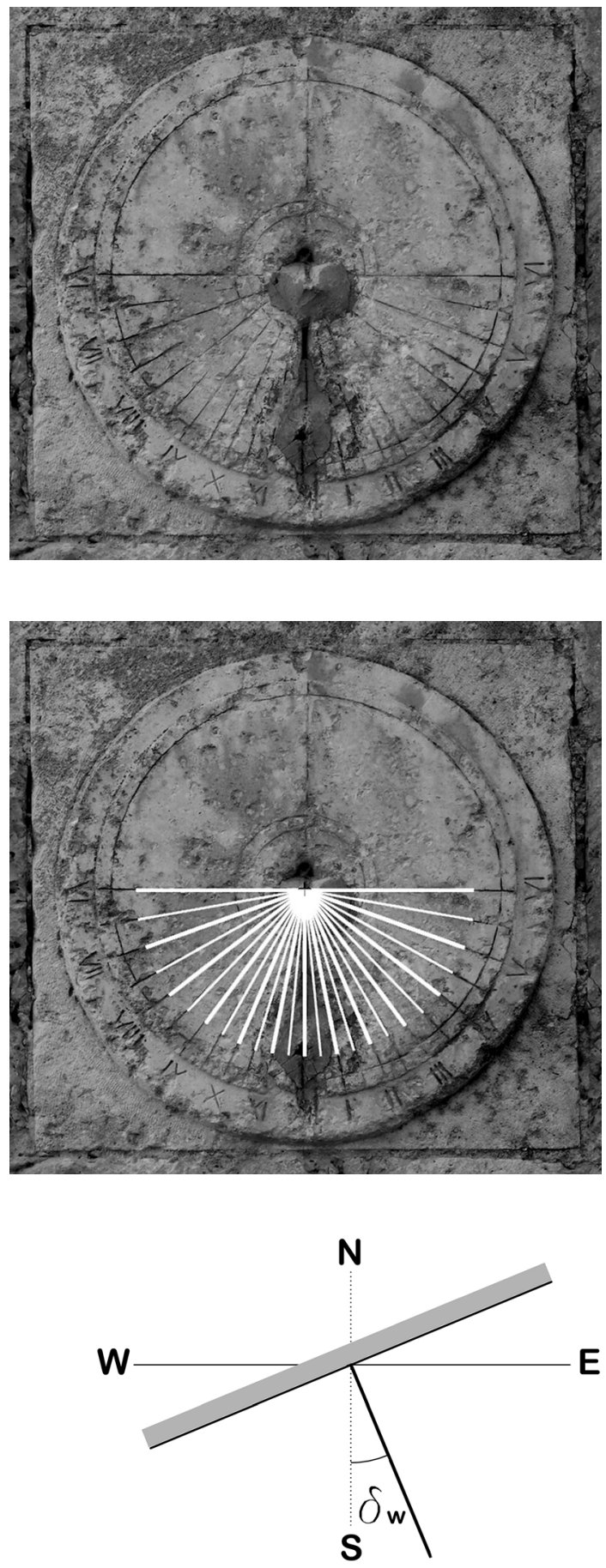
Fig. 6 Hour lines for

$\varphi=42.03^{\circ}$, wall facing SouthWest $\left(\delta_{w}=-6.6^{\circ}\right)$

Fig. 7 Celestial sphere from the observer (point V).

Interference of the wall at the instants of sunrise and sunset
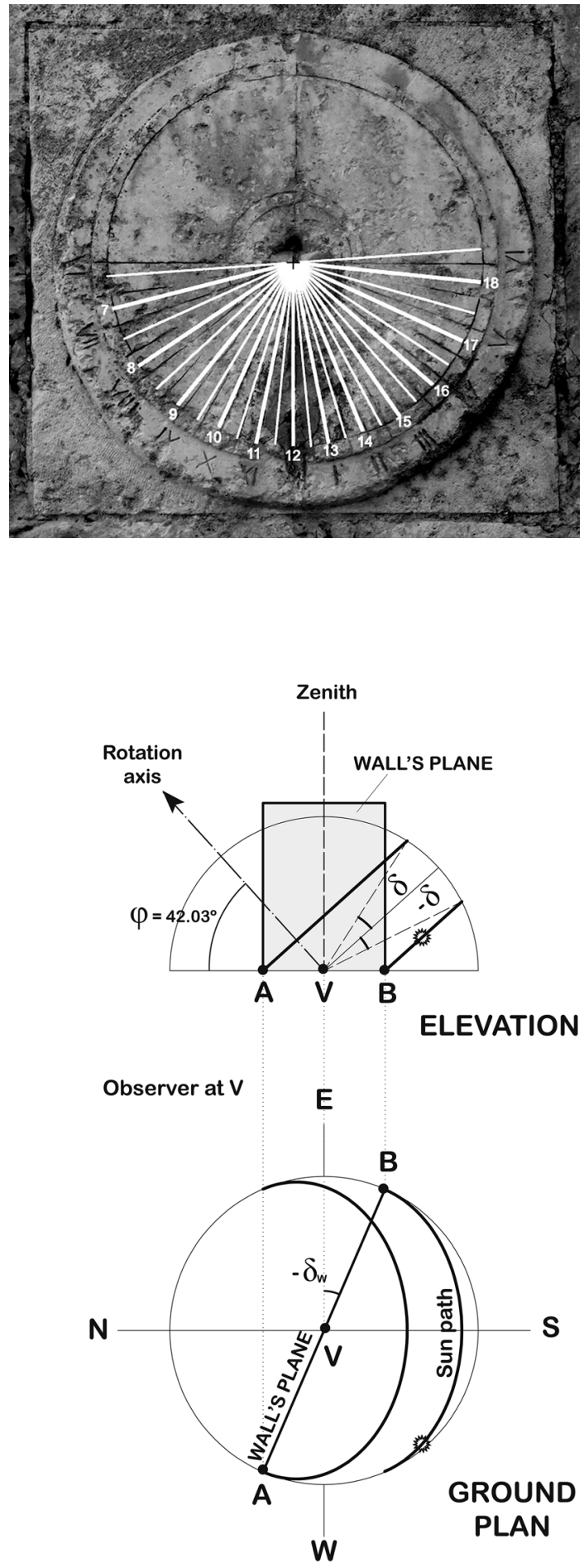


\section{Daylight Intervals due to the Dial's Orientation}

If we represent the celestial sphere in orthographic projections centred at an observer at point V (the sundial's location, as stated before), we can see the interference of the wall with the Sun at sunrise and sunset due to its orientation (Fig. 7). We will assume some simplifications: solar declination ${ }^{3} \delta$ as invariable throughout the day, and absence of atmospheric refraction. Instants of sunrise and sunset will be those when the centre of the Sun is placed on the horizon line.

In order to perform the calculations, we shall use the well-known astronomical formulae for sun's azimuth's and elevation (Meeus 1998):

Sun elevation $\hat{e}$ :

$$
\sin \hat{e}=\cos \omega \cos \delta \cos \varphi+\sin \varphi \sin \delta .
$$

with: $\omega=$ sun's hour angle, $\varphi=$ observer's latitude (for Lerma's sundial, $\left.\varphi=42.03^{\circ}\right), \delta=$ sun's declination

Solar azimuth $\gamma$ (measured from North and clockwise):

$$
\cos \gamma=\frac{\sin \delta-\sin \varphi \sin \hat{e}}{\cos \varphi \cos \hat{e}}
$$

At sunrise and sunset, $\hat{e}=0$, so, from Eq. 1:

$$
\cos \omega=-\tan \varphi \tan \delta
$$

And from Eq. 2:

$$
\cos \gamma=\frac{\sin \delta}{\cos \varphi}
$$

The wall azimuth of Lerma's sundial can be taken as $\gamma=90^{\circ}-\delta_{w}=96.6^{\circ}$ at sunrise and $\gamma=90^{\circ}-\delta_{w}+180^{\circ}=276.6^{\circ}$ at sunset, so from Eq.4 we can easily obtain $\delta$, taking into account that in this case $\varphi=42.026944^{\circ}$.

Therefore,

$$
\delta_{1}=-4.898^{\circ} \text { (sunrise) } \quad \delta_{2}=4.898^{\circ} \text { (sunset) } .
$$

If we have a look at any almanac for 2017 or, better, if we use the NOAA on-line application (NOAA 2017), dates for these declinations can be obtained. Other interactive almanacs, such as Multiyear Interactive Computer Almanac (U.S. Naval Observatory 2005), can also be helpful. The inputs are noon for Lerma (longitude $\left.3.76^{\circ} \mathrm{W}\right)$, at 12:00 local time, and Time Zone +1 .

According to NOAA application for 2017: $\delta_{1}$ corresponds to 8 March and 5 October $(\delta<0)$, and in these dates the sun's path cuts the base of the wall at B in the instant of sunrise; $\delta_{2}$ corresponds to 2 April and 10 September $(\delta>0)$, and in these dates, the sun's path intersects the wall's basis at A (Fig. 7) in the sunset (Fig. 7). Therefore, in the intervals from 1 January to 8 March and from 5 October to 31 December, the observer located at point $\mathrm{V}$ on the dial can see the sunrise, and

\footnotetext{
3 Solar declination is called $\alpha$ in some books on sundials. We prefer the astronomical notation $\delta$ despite its resemblance with $\delta_{w}: \alpha$ is used in astronomy for right ascension.
} 
the same observer can see the sunset in the intervals from 1 January to 2 April and from 10 September to 31 December.

Local solar times $\left(\mathrm{H}_{\mathrm{s}}\right)^{4}$ for sunrise and sunset can be obtained from the expression:

$$
\omega=\left(H_{s}-12\right) \cdot 15
$$

which we transform for our calculations as:

$$
H_{s}=12+\frac{\omega}{15}
$$

Therefore, taking into account Eq. 3,

$$
H_{s}=12+\arccos (-\tan \varphi \tan \delta)
$$

For the dates when sunrise or sunset cannot be seen from the observer, we can calculate the instants of Sun's disappearing behind the wall using the astronomical expression:

$$
\tan \gamma=\frac{\sin \omega}{\sin \varphi \cos \omega-\tan \delta \cos \varphi}
$$

where $\gamma$ is the azimuth of the wall's plane. Note that ${ }^{5}$

$$
\gamma=\delta_{W}+90^{\circ}
$$

Equation 7 is commonly used in astronomy. It is quoted in (Meeus 1998), (Duffie and Beckman 2013), (Blanco-Muriel et al. 2001), and others, and is extensively analysed in (Sproul 2007). In this case, we know $\gamma$, so starting from the previous Eq. 7, we can transform it to directly obtain $\omega$ :

$$
\omega=\arccos \left(\frac{\tan ^{2} \gamma \sin \varphi \cos \varphi \tan \delta \pm \sqrt{\tan ^{2} \gamma \sin ^{2} \varphi-\tan ^{2} \gamma \tan ^{2} \delta \cos ^{2} \varphi+1}}{\tan ^{2} \gamma \sin ^{2} \varphi+1}\right)
$$

For each $\delta$ we obtain two values of $\omega$, that is, $\omega_{1}$ and $\omega_{2}$. Therefore, the hours of sunrise and sunset will be again:

$$
H_{s}=12-\frac{1}{15} \omega_{1} \text { and } H_{s}=12+\frac{1}{15} \omega_{2}
$$

The obtained values are shown in Table 1 and Table 2, where decimal fractions of hours are used instead of the hh.mm.ss format. According to the Tables, the earliest solar hour in the morning would correspond to 6.321 (6:19 AM), and the later one at 18.325 (6:19 PM), values that allow us to limit our later analysis of errors. Values are shaded for those dates in which the solar path intersects the plane of the wall. The difference in the dates of the shaded values in the Tables is due to the orientation of the dial. Note that, for the same date, it may be the case that we apply the method based on Eq. 6 for sunrise and that based on Eq. 8 for sunset.

\footnotetext{
${ }^{4} \mathrm{H}_{\mathrm{s}}$ is commonly named $L S T$ in astronomy books.

5 This expression matches with the principle that the Sun is behind the dial if its azimuth differs from the dial's declination by more than $90^{\circ}$ (Oglesby 2004).
} 
Table 1 Earliest hours of direct sunlight on the dial

\begin{tabular}{|c|c|c|c|c|c|c|c|c|c|c|c|c|}
\hline \multicolumn{13}{|c|}{ Earliest hours of sunlight over the sundial. Colegiata de Lerma } \\
\hline date & Jan & Feb & Mar & $\overline{A p r}$ & May & Jun & Jul & Aug & Sep & Oct & Nov & Dec \\
\hline 1 & 7.497 & 7.065 & 6.450 & 6.997 & 7.806 & 8.411 & 8.504 & 8.033 & 7.253 & 6.410 & 6.902 & 7.413 \\
\hline 2 & 7.490 & 7.045 & 6.427 & 7.026 & 7.830 & 8.424 & 8.497 & 8.011 & 7.225 & 6.381 & 6.923 & 7.424 \\
\hline 3 & 7.482 & 7.025 & 6.403 & 7.054 & 7.854 & 8.435 & 8.490 & 7.989 & 7.198 & 6.353 & 6.944 & 7.435 \\
\hline 4 & 7.474 & 7.005 & 6.380 & 7.082 & 7.878 & 8.447 & 8.481 & 7.966 & 7.170 & 6.325 & 6.964 & 7.445 \\
\hline 5 & 7.466 & 6.985 & 6.356 & 7.110 & 7.902 & 8.457 & 8.472 & 7.943 & 7.143 & 6.295 & 6.985 & 7.455 \\
\hline 6 & 7.457 & 6.964 & 6.332 & 7.138 & 7.926 & 8.467 & 8.463 & 7.920 & 7.115 & 6.318 & 7.005 & 7.464 \\
\hline 7 & 7.447 & 6.943 & 6.309 & 7.166 & 7.949 & 8.476 & 8.452 & 7.897 & 7.087 & 6.341 & 7.025 & 7.472 \\
\hline 8 & 7.437 & 6.922 & 6.308 & 7.194 & 7.972 & 8.485 & 8.441 & 7.873 & 7.059 & 6.364 & 7.045 & 7.480 \\
\hline 9 & 7.427 & 6.901 & 6.336 & 7.222 & 7.995 & 8.493 & 8.430 & 7.849 & 7.031 & 6.388 & 7.064 & 7.488 \\
\hline 10 & 7.415 & 6.880 & 6.365 & 7.250 & 8.017 & 8.501 & 8.418 & 7.825 & 7.004 & 6.411 & 7.083 & 7.495 \\
\hline 11 & 7.404 & 6.858 & 6.394 & 7.278 & 8.039 & 8.508 & 8.406 & 7.801 & 6.976 & 6.434 & 7.102 & 7.501 \\
\hline 12 & 7.392 & 6.837 & 6.423 & 7.305 & 8.061 & 8.514 & 8.393 & 7.777 & 6.948 & 6.457 & 7.121 & 7.507 \\
\hline 13 & 7.379 & 6.815 & 6.452 & 7.333 & 8.083 & 8.519 & 8.379 & 7.752 & 6.919 & 6.480 & 7.140 & 7.512 \\
\hline 14 & 7.366 & 6.793 & 6.481 & 7.360 & 8.104 & 8.524 & 8.365 & 7.727 & 6.891 & 6.503 & 7.158 & 7.517 \\
\hline 15 & 7.353 & 6.771 & 6.509 & 7.388 & 8.124 & 8.528 & 8.350 & 7.702 & 6.863 & 6.526 & 7.176 & 7.521 \\
\hline 16 & 7.339 & 6.748 & 6.538 & 7.415 & 8.145 & 8.532 & 8.335 & 7.677 & 6.835 & 6.549 & 7.193 & 7.525 \\
\hline 17 & 7.324 & 6.726 & 6.567 & 7.442 & 8.165 & 8.535 & 8.319 & 7.651 & 6.807 & 6.572 & 7.210 & 7.528 \\
\hline 18 & 7.310 & 6.704 & 6.596 & 7.469 & 8.184 & 8.537 & 8.303 & 7.625 & 6.779 & 6.594 & 7.227 & 7.530 \\
\hline 19 & 7.294 & 6.681 & 6.625 & 7.496 & 8.204 & 8.539 & 8.287 & 7.600 & 6.750 & 6.617 & 7.244 & 7.531 \\
\hline 20 & 7.279 & 6.658 & 6.654 & 7.523 & 8.222 & 8.539 & 8.269 & 7.574 & 6.722 & 6.640 & 7.260 & 7.533 \\
\hline 21 & 7.263 & 6.635 & 6.682 & 7.549 & 8.241 & 8.540 & 8.252 & 7.548 & 6.694 & 6.662 & 7.276 & 7.533 \\
\hline 22 & 7.246 & 6.613 & 6.711 & 7.576 & 8.259 & 8.539 & 8.234 & 7.521 & 6.665 & 6.685 & 7.292 & 7.533 \\
\hline 23 & 7.230 & 6.590 & 6.740 & 7.602 & 8.276 & 8.538 & 8.216 & 7.495 & 6.637 & 6.707 & 7.307 & 7.532 \\
\hline 24 & 7.213 & 6.567 & 6.769 & 7.628 & 8.293 & 8.536 & 8.197 & 7.469 & 6.608 & 6.729 & 7.322 & 7.531 \\
\hline 25 & 7.195 & 6.543 & 6.797 & 7.654 & 8.310 & 8.534 & 8.178 & 7.442 & 6.580 & 6.751 & 7.336 & 7.529 \\
\hline 26 & 7.178 & 6.520 & 6.826 & 7.680 & 8.326 & 8.530 & 8.158 & 7.415 & 6.552 & 6.773 & 7.350 & 7.526 \\
\hline 27 & 7.160 & 6.497 & 6.855 & 7.705 & 8.341 & 8.526 & 8.138 & 7.388 & 6.523 & 6.795 & 7.363 & 7.523 \\
\hline 28 & 7.141 & 6.474 & 6.883 & 7.731 & 8.356 & 8.522 & 8.118 & 7.361 & 6.495 & 6.817 & 7.377 & 7.519 \\
\hline 29 & 7.123 & & 6.912 & 7.756 & 8.371 & 8.517 & 8.097 & 7.334 & 6.466 & 6.838 & 7.389 & 7.515 \\
\hline 30 & 7.104 & & 6.940 & 7.781 & 8.385 & 8.511 & 8.076 & 7.307 & 6.438 & 6.860 & 7.401 & 7.510 \\
\hline 31 & 7.084 & & 6.969 & & 8.398 & & 8.055 & 7.280 & & 6.881 & & 7.504 \\
\hline
\end{tabular}


Table 2 Latest hours of direct sunlight on the dial

\begin{tabular}{|c|c|c|c|c|c|c|c|c|c|c|c|c|}
\hline \multicolumn{13}{|c|}{ Last hours of sunlight over the sundial. Colegiata de Lerma } \\
\hline date & Jan & Feb & Mar & Apr & May & Jun & Jul & Aug & Sep & Oct & Nov & Dec \\
\hline 1 & 16.503 & 16.935 & 17.550 & 18.283 & 17.502 & 16.896 & 16.803 & 17.274 & 18.055 & 17.799 & 17.098 & 16.587 \\
\hline 2 & 16.510 & 16.955 & 17.573 & 18.306 & 17.477 & 16.884 & 16.810 & 17.296 & 18.082 & 17.775 & 17.077 & 16.576 \\
\hline 3 & 16.518 & 16.975 & 17.597 & 18.254 & 17.453 & 16.872 & 16.818 & 17.319 & 18.110 & 17.752 & 17.056 & 16.565 \\
\hline 4 & 16.526 & 16.995 & 17.620 & 18.225 & 17.429 & 16.861 & 16.826 & 17.341 & 18.137 & 17.729 & 17.036 & 16.555 \\
\hline 5 & 16.534 & 17.015 & 17.644 & 18.197 & 17.405 & 16.850 & 16.835 & 17.364 & 18.165 & 17.705 & 17.015 & 16.545 \\
\hline 6 & 16.543 & 17.036 & 17.668 & 18.169 & 17.382 & 16.840 & 16.845 & 17.387 & 18.192 & 17.682 & 16.995 & 16.536 \\
\hline 7 & 16.553 & 17.057 & 17.691 & 18.141 & 17.358 & 16.831 & 16.855 & 17.410 & 18.220 & 17.659 & 16.975 & 16.528 \\
\hline 8 & 16.563 & 17.078 & 17.715 & 18.113 & 17.335 & 16.822 & 16.866 & 17.434 & 18.248 & 17.636 & 16.955 & 16.520 \\
\hline 9 & 16.573 & 17.099 & 17.739 & 18.085 & 17.313 & 16.814 & 16.877 & 17.458 & 18.276 & 17.612 & 16.936 & 16.512 \\
\hline 10 & 16.585 & 17.120 & 17.762 & 18.057 & 17.290 & 16.807 & 16.889 & 17.482 & 18.288 & 17.589 & 16.917 & 16.505 \\
\hline 11 & 16.596 & 17.142 & 17.786 & 18.030 & 17.268 & 16.800 & 16.902 & 17.506 & 18.265 & 17.566 & 16.898 & 16.499 \\
\hline 12 & 16.608 & 17.163 & 17.810 & 18.002 & 17.246 & 16.794 & 16.915 & 17.531 & 18.242 & 17.543 & 16.879 & 16.493 \\
\hline 13 & 16.621 & 17.185 & 17.834 & 17.974 & 17.225 & 16.788 & 16.928 & 17.556 & 18.219 & 17.520 & 16.860 & 16.488 \\
\hline 14 & 16.634 & 17.207 & 17.857 & 17.947 & 17.204 & 16.783 & 16.943 & 17.580 & 18.196 & 17.497 & 16.842 & 16.483 \\
\hline 15 & 16.647 & 17.229 & 17.881 & 17.920 & 17.183 & 16.779 & 16.957 & 17.606 & 18.173 & 17.474 & 16.824 & 16.479 \\
\hline 16 & 16.661 & 17.252 & 17.905 & 17.892 & 17.163 & 16.775 & 16.972 & 17.631 & 18.149 & 17.451 & 16.807 & 16.475 \\
\hline 17 & 16.676 & 17.274 & 17.929 & 17.865 & 17.143 & 16.772 & 16.988 & 17.656 & 18.126 & 17.428 & 16.790 & 16.472 \\
\hline 18 & 16.690 & 17.296 & 17.952 & 17.838 & 17.123 & 16.770 & 17.004 & 17.682 & 18.103 & 17.406 & 16.773 & 16.470 \\
\hline 19 & 16.706 & 17.319 & 17.976 & 17.812 & 17.104 & 16.769 & 17.021 & 17.708 & 18.080 & 17.383 & 16.756 & 16.469 \\
\hline 20 & 16.721 & 17.342 & 18.000 & 17.785 & 17.085 & 16.768 & 17.038 & 17.734 & 18.056 & 17.360 & 16.740 & 16.467 \\
\hline 21 & 16.737 & 17.365 & 18.024 & 17.758 & 17.067 & 16.768 & 17.055 & 17.760 & 18.033 & 17.338 & 16.724 & 16.467 \\
\hline 22 & 16.754 & 17.387 & 18.047 & 17.732 & 17.049 & 16.768 & 17.073 & 17.786 & 18.010 & 17.315 & 16.708 & 16.467 \\
\hline 23 & 16.770 & 17.410 & 18.071 & 17.706 & 17.031 & 16.769 & 17.092 & 17.812 & 17.986 & 17.293 & 16.693 & 16.468 \\
\hline 24 & 16.787 & 17.433 & 18.095 & 17.679 & 17.014 & 16.771 & 17.111 & 17.839 & 17.963 & 17.271 & 16.678 & 16.469 \\
\hline 25 & 16.805 & 17.457 & 18.118 & 17.654 & 16.998 & 16.774 & 17.130 & 17.865 & 17.939 & 17.249 & 16.664 & 16.471 \\
\hline 26 & 16.822 & 17.480 & 18.142 & 17.628 & 16.982 & 16.777 & 17.149 & 17.892 & 17.916 & 17.227 & 16.650 & 16.474 \\
\hline 27 & 16.840 & 17.503 & 18.166 & 17.602 & 16.966 & 16.781 & 17.169 & 17.919 & 17.893 & 17.205 & 16.637 & 16.477 \\
\hline 28 & 16.859 & 17.526 & 18.189 & 17.577 & 16.951 & 16.785 & 17.190 & 17.946 & 17.869 & 17.183 & 16.623 & 16.481 \\
\hline 29 & 16.877 & & 18.213 & 17.552 & 16.936 & 16.791 & 17.210 & 17.973 & 17.846 & 17.162 & 16.611 & 16.485 \\
\hline 30 & 16.896 & & 18.236 & 17.527 & 16.922 & 16.796 & 17.231 & 18.000 & 17.822 & 17.140 & 16.599 & 16.490 \\
\hline 31 & 16.916 & & 18.260 & & 16.909 & & 17.253 & 18.027 & 17.799 & 17.119 & & 16.496 \\
\hline
\end{tabular}




\section{Shadow Cast by Architectural Elements and Nearby Trees}

Close to our sundial there are several elements that cast their shadow on it in the early hours of the morning, and these hours vary throughout the year. These elements are a wall (oriented approximately North-South), almost perpendicular to the main façade, and a row of trees (see Figs. 1 and 2).

The solar dial is located $3 \mathrm{~m}$ from the ground level. The maximum height from the upper level of the nearby wall related to the dial's level is $8.25 \mathrm{~m}$ and the minimum height is $4.60 \mathrm{~m}$. On the same reference plane, the trees have a maximum height of about $6 \mathrm{~m}$. These values, and their approximate distances to the sundial in the horizontal plane, serve us to draw a graph including the skyline of architectural elements and trees. It is useful to place this skyline on an graph of sunshine for our latitude, which we can also obtain through the aforementioned sources (Blateyron 2017; Casalegno 2017), or different on-line applications (Sun Earth Tools 2017), taking into account that we must consider solar local hours. In Fig. 8 we see the graph with the superimposed profile, which we can use to graphically obtain the values to correct the sunshine hours.

Table 3 takes into account the values graphically obtained for sunrise with the help of Fig. 8. This Table 3 now replaces Table 2. Table 1 has no modifications.

Based on Table 1 and Table 3, we can obtain the graphic of Fig. 9, where theoretical values of sunrise are dashed and the corrected ones due to the surrounding architectonic elements are marked as a solid line.

\section{Derivation Procedure for the Calculation of Errors}

Now we are going to analyse the possible errors of reading for different hypothesis related to the orientation and angular features of a gnomon. Our calculations will take Fig. 10 as the starting point.

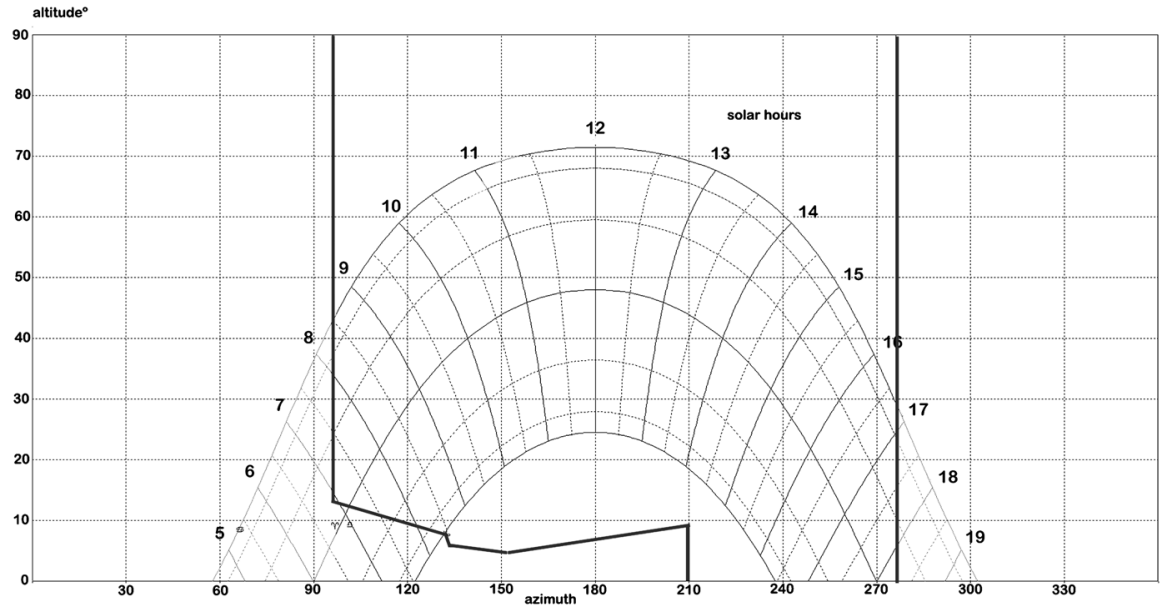

Fig. 8 Sunlight graph with the upper lines of trees and adjacent wall superimposed 
Table 3 Earliest hours of direct sunlight on the dial corrected as a function of adjacent wall and trees

\begin{tabular}{|c|c|c|c|c|c|c|c|c|c|c|c|c|}
\hline \multicolumn{13}{|c|}{$\begin{array}{r}\text { First hours of sunlight over the sundial. Colegiata d } \\
\text { architectonical landscape) }\end{array}$} \\
\hline date & Jan & Feb & Mar & Apr & May & Jun & Jul & Aug & Sep & Oct & Nov & Dec \\
\hline 1 & 8.304 & 7.984 & 7.473 & 6.997 & 7.806 & 8.411 & 8.504 & 8.033 & 7.253 & 7.260 & 7.803 & 8.228 \\
\hline 2 & 8.297 & 7.967 & 7.454 & 7.026 & 7.830 & 8.424 & 8.497 & 8.011 & 7.225 & 7.277 & 7.820 & 8.236 \\
\hline 3 & 8.291 & 7.949 & 7.434 & 7.054 & 7.854 & 8.435 & 8.490 & 7.989 & 7.198 & 7.295 & 7.837 & 8.243 \\
\hline 4 & 8.284 & 7.931 & 7.414 & 7.082 & 7.878 & 8.447 & 8.481 & 7.966 & 7.170 & 7.313 & 7.854 & 8.251 \\
\hline 5 & 8.277 & 7.914 & 7.395 & 7.110 & 7.902 & 8.457 & 8.472 & 7.943 & 7.143 & 7.331 & 7.871 & 8.259 \\
\hline 6 & 8.270 & 7.896 & 7.375 & 7.138 & 7.926 & 8.467 & 8.463 & 7.920 & 7.115 & 7.348 & 7.888 & 8.266 \\
\hline 7 & 8.263 & 7.879 & 7.355 & 7.166 & 7.949 & 8.476 & 8.452 & 7.897 & 7.087 & 7.366 & 7.905 & 8.274 \\
\hline 8 & 8.256 & 7.861 & 7.336 & 7.194 & 7.972 & 8.485 & 8.441 & 7.873 & 7.059 & 7.384 & 7.922 & 8.281 \\
\hline 9 & 8.249 & 7.843 & 7.316 & 7.222 & 7.995 & 8.493 & 8.430 & 7.849 & 7.031 & 7.402 & 7.939 & 8.289 \\
\hline 10 & 8.242 & 7.826 & 7.296 & 7.250 & 8.017 & 8.501 & 8.418 & 7.825 & 7.004 & 7.419 & 7.956 & 8.297 \\
\hline 11 & 8.236 & 7.808 & 7.277 & 7.278 & 8.039 & 8.508 & 8.406 & 7.801 & 7.024 & 7.437 & 7.973 & 8.304 \\
\hline 12 & 8.229 & 7.791 & 7.257 & 7.305 & 8.061 & 8.514 & 8.393 & 7.777 & 7.045 & 7.455 & 7.990 & 8.312 \\
\hline 13 & 8.222 & 7.773 & 7.237 & 7.333 & 8.083 & 8.519 & 8.379 & 7.752 & 7.051 & 7.473 & 8.007 & 8.319 \\
\hline 14 & 8.215 & 7.756 & 7.218 & 7.360 & 8.104 & 8.524 & 8.365 & 7.727 & 7.056 & 7.490 & 8.024 & 8.327 \\
\hline 15 & 8.208 & 7.738 & 7.198 & 7.388 & 8.124 & 8.528 & 8.350 & 7.702 & 7.062 & 7.508 & 8.041 & 8.334 \\
\hline 16 & 8.201 & 7.720 & 7.179 & 7.415 & 8.145 & 8.532 & 8.335 & 7.677 & 7.067 & 7.526 & 8.058 & 8.342 \\
\hline 17 & 8.194 & 7.703 & 7.159 & 7.442 & 8.165 & 8.535 & 8.319 & 7.651 & 7.073 & 7.544 & 8.075 & 8.350 \\
\hline 18 & 8.187 & 7.685 & 7.139 & 7.469 & 8.184 & 8.537 & 8.303 & 7.625 & 7.078 & 7.561 & 8.092 & 8.357 \\
\hline 19 & 8.181 & 7.668 & 7.120 & 7.496 & 8.204 & 8.539 & 8.287 & 7.600 & 7.084 & 7.579 & 8.109 & 8.365 \\
\hline 20 & 8.174 & 7.650 & 7.100 & 7.523 & 8.222 & 8.539 & 8.269 & 7.574 & 7.089 & 7.597 & 8.126 & 8.372 \\
\hline 21 & 8.167 & 7.630 & 7.079 & 7.549 & 8.241 & 8.540 & 8.252 & 7.548 & 7.095 & 7.615 & 8.143 & 8.380 \\
\hline 22 & 8.160 & 7.611 & 7.058 & 7.576 & 8.259 & 8.539 & 8.234 & 7.521 & 7.100 & 7.632 & 8.160 & 8.373 \\
\hline 23 & 8.142 & 7.591 & 7.037 & 7.602 & 8.276 & 8.538 & 8.216 & 7.495 & 7.118 & 7.650 & 8.168 & 8.366 \\
\hline 24 & 8.125 & 7.571 & 7.016 & 7.628 & 8.293 & 8.536 & 8.197 & 7.469 & 7.135 & 7.667 & 8.175 & 8.359 \\
\hline 25 & 8.107 & 7.552 & 6.996 & 7.654 & 8.310 & 8.534 & 8.178 & 7.442 & 7.153 & 7.684 & 8.183 & 8.353 \\
\hline 26 & 8.090 & 7.532 & 6.975 & 7.680 & 8.326 & 8.530 & 8.158 & 7.415 & 7.171 & 7.701 & 8.190 & 8.346 \\
\hline 27 & 8.072 & 7.512 & 6.954 & 7.705 & 8.341 & 8.526 & 8.138 & 7.388 & 7.189 & 7.718 & 8.198 & 8.339 \\
\hline 28 & 8.054 & 7.493 & 6.933 & 7.731 & 8.356 & 8.522 & 8.118 & 7.361 & 7.206 & 7.735 & 8.206 & 8.332 \\
\hline 29 & 8.037 & & 6.912 & 7.756 & 8.371 & 8.517 & 8.097 & 7.334 & 7.224 & 7.752 & 8.213 & 8.325 \\
\hline 30 & 8.019 & & 6.940 & 7.781 & 8.385 & 8.511 & 8.076 & 7.307 & 7.242 & 7.769 & 8.221 & 8.318 \\
\hline 31 & 8.002 & & 6.969 & & 8.398 & & 8.055 & 7.280 & & 7.786 & & 8.311 \\
\hline
\end{tabular}




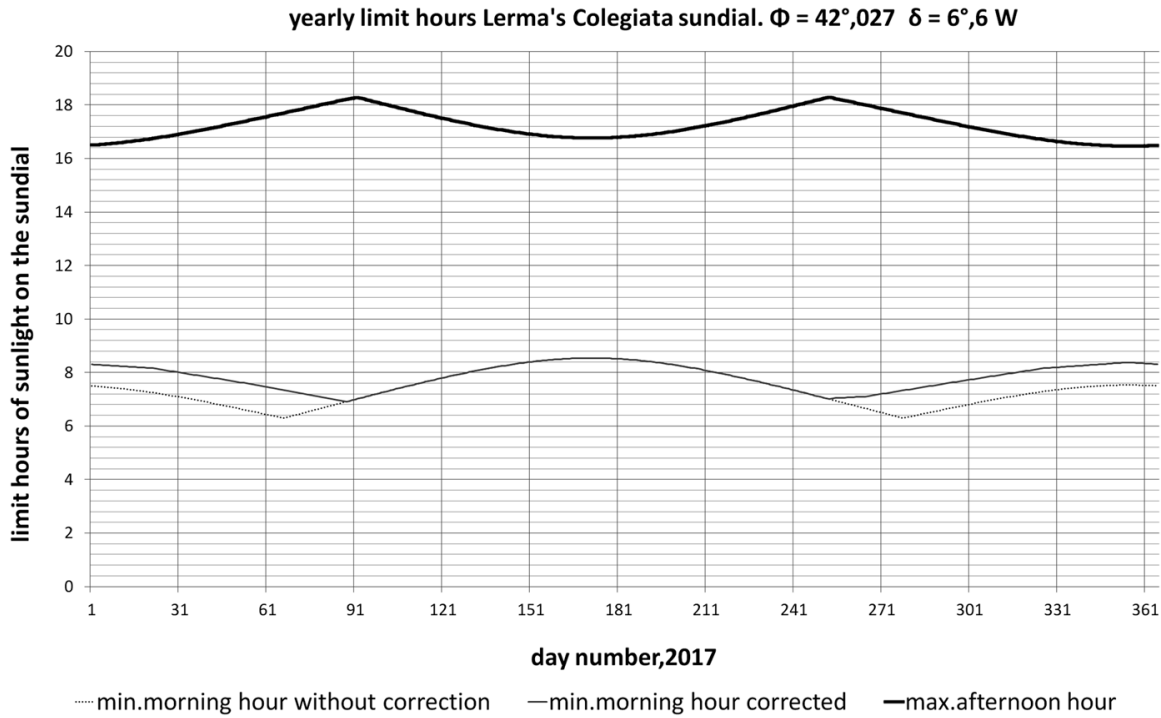

Fig. 9 Variation along the year of earliest and latest hours of direct sunlight on the dial. Dashed lines are those for sunrise without surrounding elements' correction

Fig. 10 Angular relationships between a generic real gnomon $\mathrm{OA}$ and an imaginary gnomon $\mathrm{O}^{\prime} \mathrm{A}$

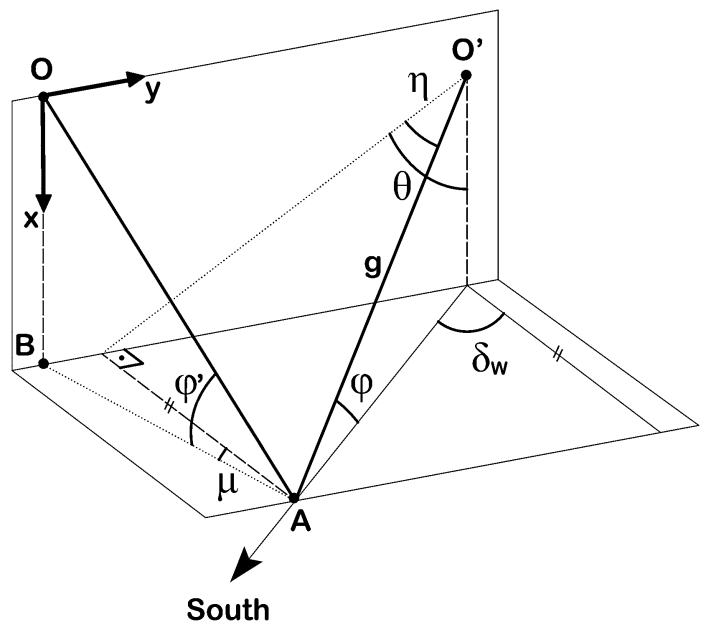

In Fig. 10, a generic incorrect gnomon is shown as OA. The lower end of the gnomon is the point $\mathrm{A}$, whose shadow will be cast on the wall. Now, let $\mathrm{O}^{\prime} \mathrm{A}$ be an imaginary correctly-oriented gnomon whose lower end is the same point A. It will be contained on a vertical plane following the North-South direction. The angle between this gnomon and the horizontal plane will be $\varphi$, the latitude of the observer.

If we call $\mathrm{A}^{\prime}$ the shadow of the point $\mathrm{A}$ on the wall, the line $\mathrm{OA}^{\prime}$ will allow us to read the faulty hour on the original dial, and the line $\mathrm{O}^{\prime} \mathrm{A}^{\prime}$ will correspond to the actual hour on our imaginary dial related to the imaginary gnomon. Usually, either 
OB or OA are known. For our derivations, we will consider OA as known. Other inputs will be $\delta_{w}, \varphi, \varphi^{\prime}$ and $\mu$, the angle between a vertical plane perpendicular to the wall and the vertical plane containing the gnomon (Fig. 10). In Lerma, as stated above, $\varphi=42.03^{\circ}$, and $\delta_{w}=-6.6^{\circ}$.

From Fig. 10, we can obtain the values $\eta$ and $\theta$, which we'll use later:

$$
\begin{gathered}
\eta=\arcsin \left(\cos \varphi \cos \delta_{W}\right) \\
\theta=\arccos \left(\frac{\sin \varphi}{\cos \eta}\right)
\end{gathered}
$$

Also:

$$
g=\frac{O A \cdot \cos \varphi^{\prime} \cos \mu}{\cos \delta_{W} \cos \varphi}
$$

Now, let us look at Fig. 11, in which $\mathrm{A}^{\prime}$ (shadow of the point A) is shown. Lines for solar hours of noon in the real and imaginary dials, $H_{s}$ and $H_{s}{ }^{\prime}$, are shown; both of them are vertical. Vectors $\rho=\mathrm{OA}^{\prime}$ and $\rho^{\prime}=\mathrm{O}^{\prime} \mathrm{A}^{\prime}$ are the shadows of real and imaginary gnomons and let us read the solar hour related to the real and imaginary dials, respectively.

Coordinates of $\mathrm{O}^{\prime}$ related to $\mathrm{O}$ are:

$$
\begin{gathered}
O_{x}^{\prime}=O A \cdot \sin \varphi^{\prime}-g \cdot \sin \varphi \\
O_{y}^{\prime}=O A \cdot \cos \varphi^{\prime} \sin \mu+g \cdot \cos \varphi \sin \delta_{W}
\end{gathered}
$$

For solar hour $H_{s}{ }^{\prime}$ in the imaginary dial, we will have an hourly angle $\omega^{\prime}$ related with that according to:

$$
H_{s}^{\prime}=12+\frac{\omega^{\prime}}{15}
$$

Which we can write as:

$$
\omega^{\prime}=\left(H_{s}^{\prime}-12\right) \cdot 15
$$

Fig. 11 Geometrical polar coordinates of $\mathrm{A}^{\prime}$ ( shadow of $\mathrm{A}$ ) in real and imaginary dials

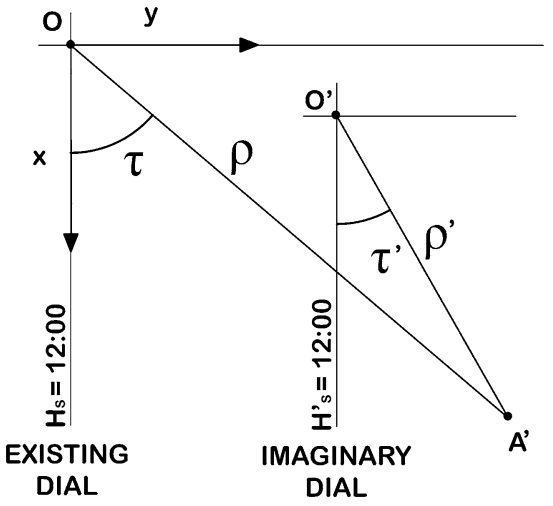


According to (Soler 1997), the angle between the vertical straight line on $\mathrm{O}^{\prime}$ (that is to say, the line for noon $\left(H_{s}^{\prime}=12: 00\right)$ in the imaginary dial) and the straight line of shadow $\mathrm{O}^{\prime} \mathrm{A}^{\prime}$ is:

$$
\cot \tau^{\prime}=\frac{\cos \delta_{W}}{\cos \varphi \tan \omega^{\prime}}-\sin \delta_{W} \tan \varphi
$$

According to the same author, the distance $\mathrm{O}^{\prime} \mathrm{A}^{\prime}$ will be:

$$
\rho^{\prime}=\frac{g \cdot \cos \delta}{\cos \delta \cos \left(\theta-\tau^{\prime}\right) \cos \eta-\sin \delta \sqrt{1-\cos ^{2}\left(\theta-\tau^{\prime}\right) \cos ^{2} \eta}}
$$

$\eta, \theta$ and $\mathrm{g}$ are those values calculated in Eq. 9, Eq. 10 and Eq. 11.

If we relate the coordinates of $\mathrm{A}^{\prime}$ to the primitive dial's origin, $\mathrm{O}$ :

$$
\begin{aligned}
& A_{x}^{\prime}=\rho^{\prime} \cos \tau^{\prime}+O_{x}^{\prime} \\
& A_{y}^{\prime}=\rho^{\prime} \sin \tau^{\prime}+O_{x}^{\prime}
\end{aligned}
$$

Therefore, the angle $\tau$ on the primitive dial can be obtained from:

$$
\tan \tau=\frac{A_{y}^{\prime}}{A_{x}^{\prime}}
$$

To obtain $\omega$ we can start again from Eq. 14, but related to the new obtained values. Therefore, taking into account that the primitive dial's marks were drawn considering an erroneous $\delta_{w}=0^{\circ}$ instead of $\delta_{w}=-6.6^{\circ}$

$$
\cot \tau=\frac{\cos \delta_{W}}{\cos \varphi \tan \omega}-\sin \delta_{W} \tan \varphi=\frac{1}{\cos \varphi \tan \omega}
$$

That is to say:

$$
\omega=\arctan \left(\frac{\tan \tau}{\cos \varphi}\right)
$$

And, according to it, the hour on our primitive dial will be:

$$
H_{s}=12+\frac{\omega}{15}
$$

Finally, the advance or delay between the actual solar hour and the hour red on our incorrect dial will be, measured in minutes:

$$
\Delta H_{s}=\left(H_{s}-H_{s}^{\prime}\right) \cdot 60
$$

\section{Results for Different Hypotheses}

The process we have just gone through allow us to graphically represent different hypothesis for the restitution of the gnomon. It is interesting to remark that the significant values are the angular ones, and variations in the numerical value of $\mathrm{OA}$ have no influence in the calculation process. OA can be taken as $\mathrm{OA}=1$ or other arbitrary values in order to perform the calculations for example, via spreadsheet. 


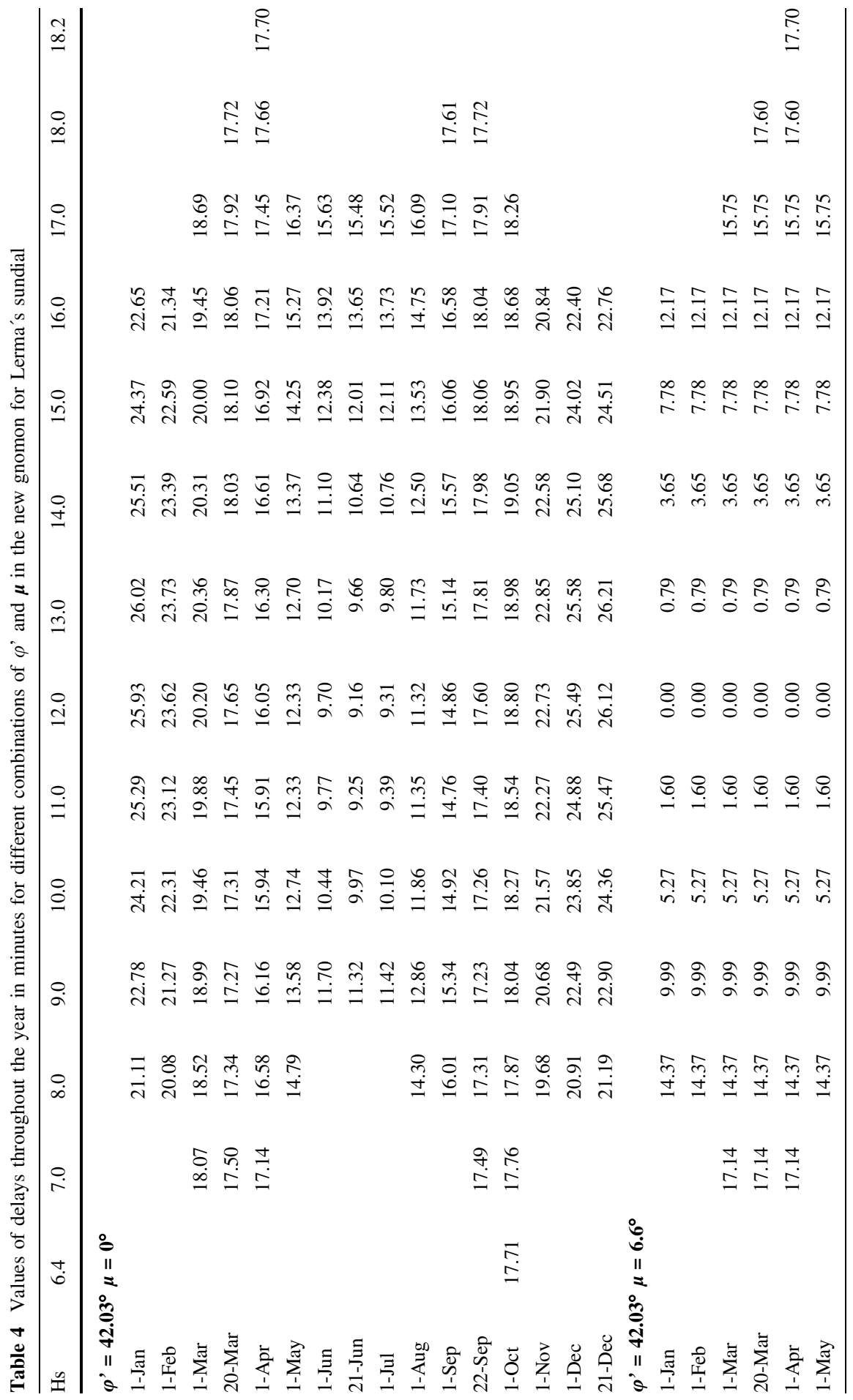




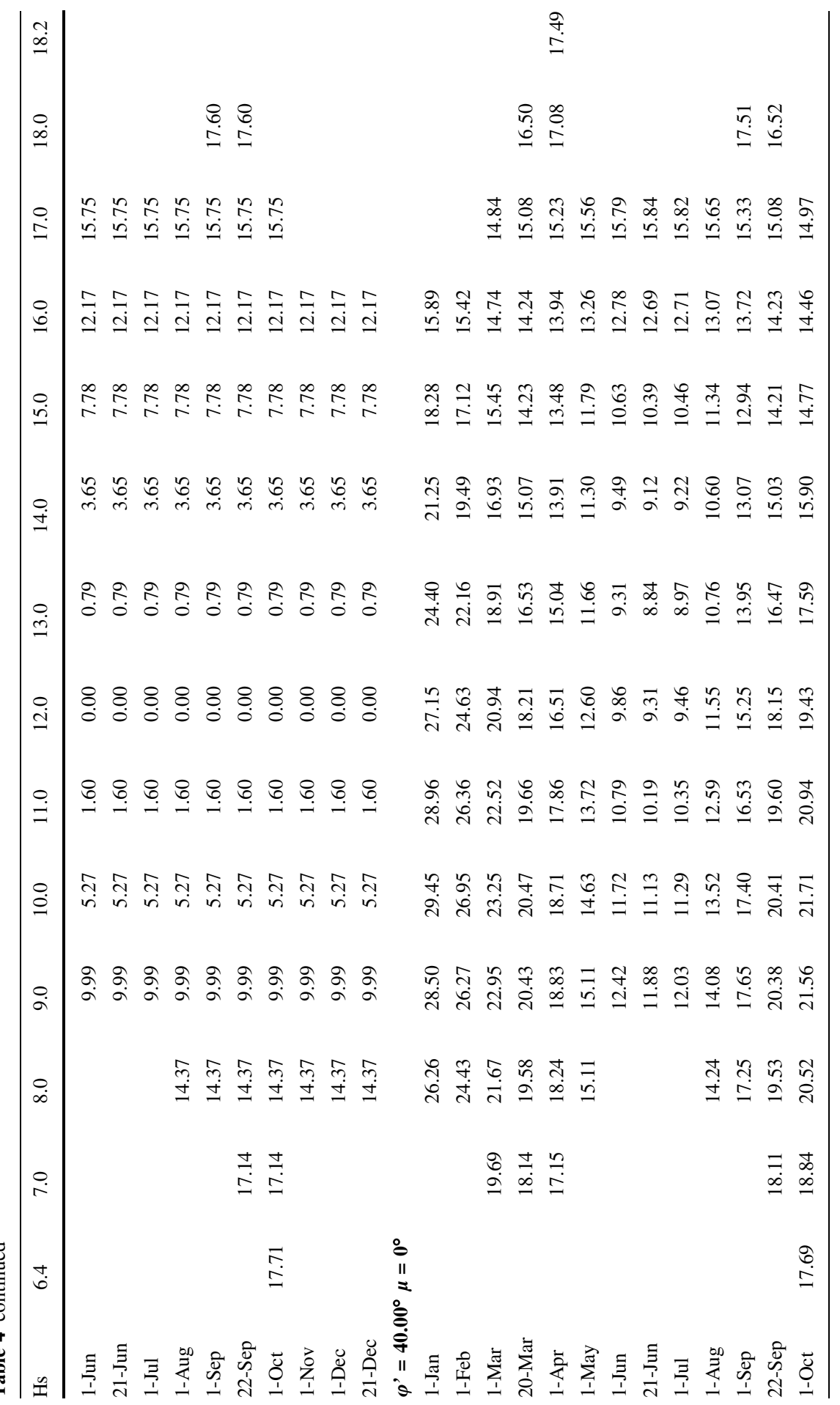




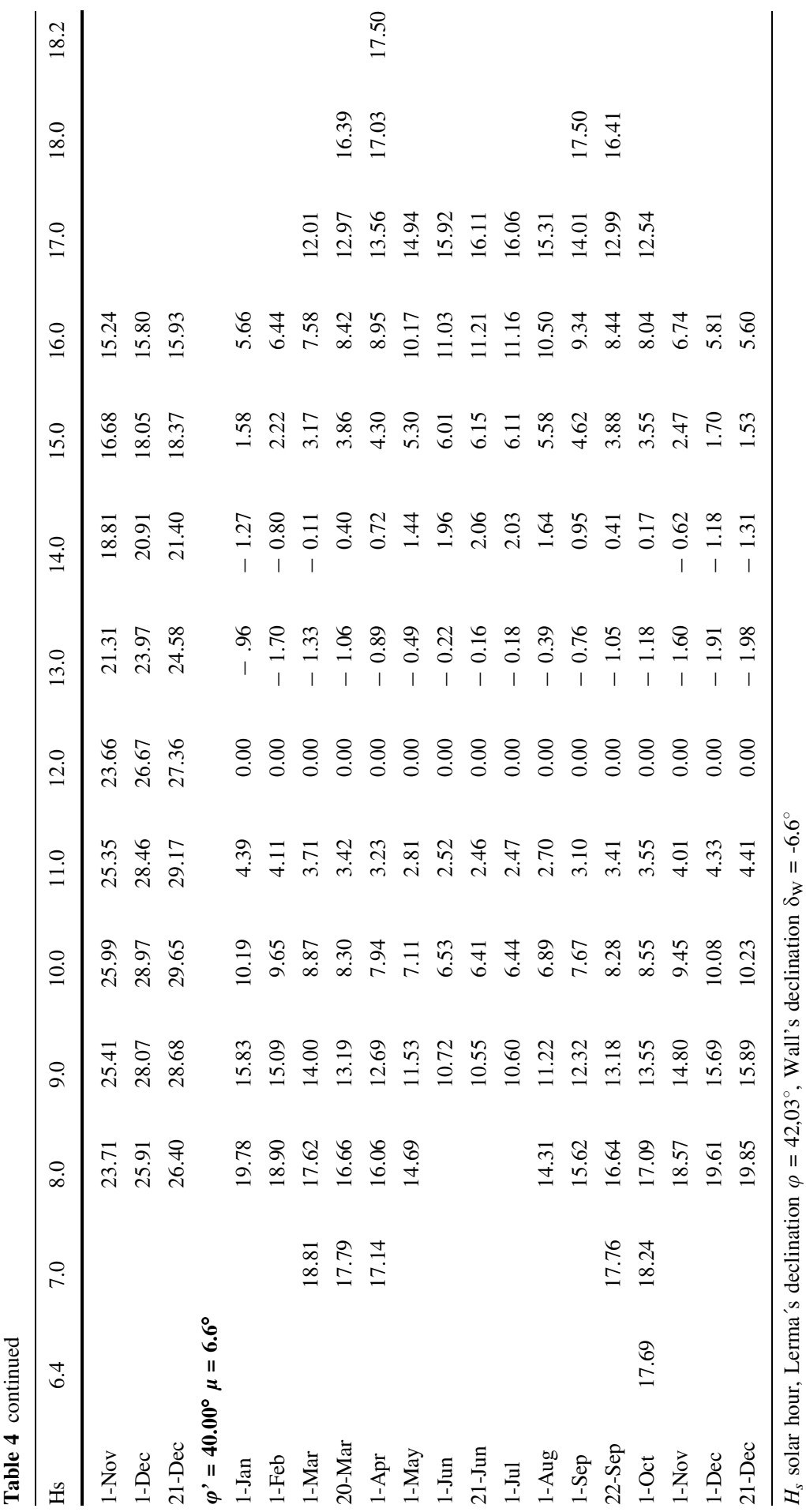




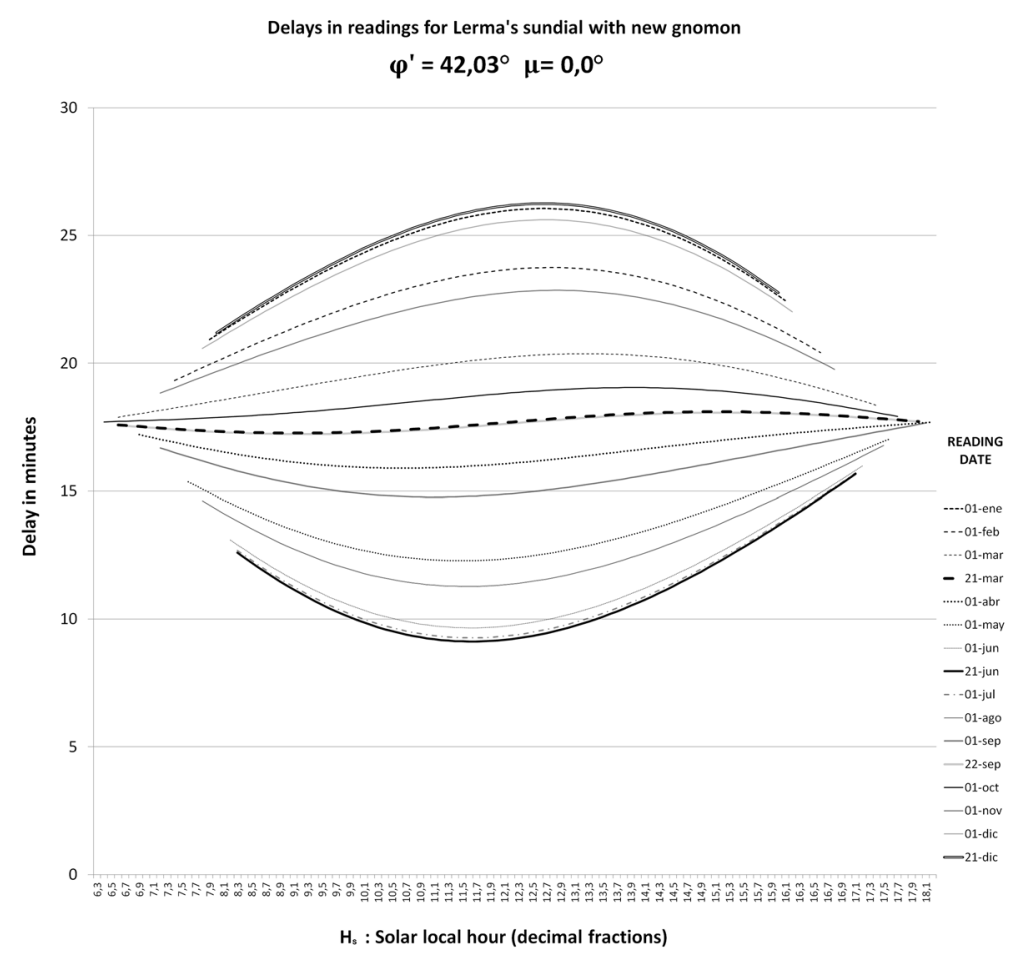

Fig. 12 Delays in readings for Lerma's sundial. $\varphi^{\prime}=42.03^{\circ}, \mu=0.0^{\circ}$

Although the graphs have been obtained for intervals of $0.1 \mathrm{~h}$, for the sake of ease of analysis and neatness Table 4 includes only significant values for intervals of $1 \mathrm{~h}$ and for the first dates of each month plus the dates of equinoxes and solstices. Note that signs of results in Eq. 19 have been inverted for clarity due to the fact that most values for Lerma were negative. Therefore, Table 4 and Figs. 12, 13, 14 and 15 show delays instead of advances. The values of $\mathrm{H}_{\mathrm{s}}$ correspond, as always, to true local solar times. In all cases, $\delta_{w}=0$, and different hypothses take into account different values for angles $\mu$ and $\varphi$ ' as defined in Fig. 10.

\section{New Gnomon Located on $\mathrm{O}$ in a Vertical Plane Perpendicular to the Wall $(\mu=0)$, with $\varphi^{\prime}=\varphi$}

In our case, this was most probably the original gnomon, now missing. The graph for delays is that of Fig. 12.

The maximum delay, $26.25 \mathrm{~min}$, corresponds to winter solstice, about $12.6 \mathrm{H}_{\mathrm{s}}$. The minimum delay, $9.12 \mathrm{~min}$, corresponds to summer solstice, about $11.6 \mathrm{H}_{\mathrm{s}}$ (again we are using decimal values for fractional hours). Daily delays increase towards noon in autumn and winter and decrease towards noon in spring and summer. During the equinoxes, values have slight variations throughout the day, remaining stable at about 18 min of delay. Note that left and right ends of the curves are cut according to the limits shown in Tables 1 and 3. 


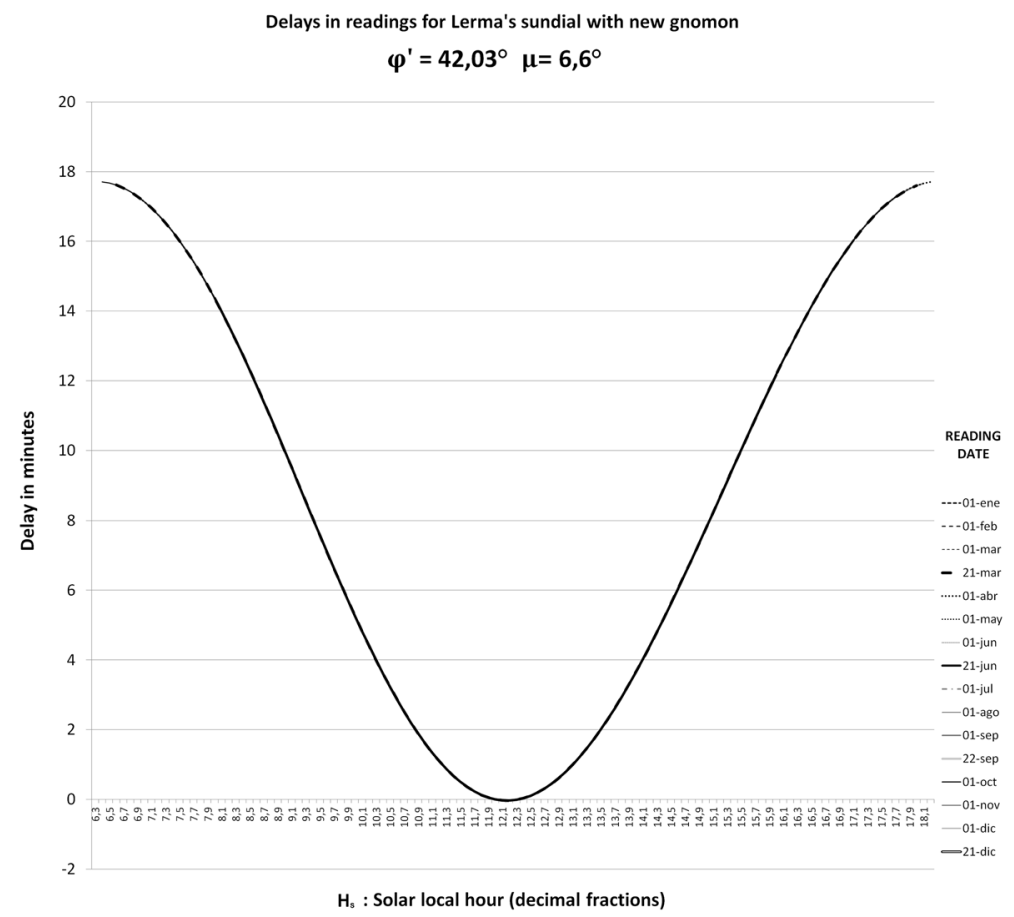

Fig. 13 Delays in readings for Lerma's sundial. $\varphi^{\prime}=42.03^{\circ}, \mu=6.6^{\circ}$

New Gnomon Placed on $O$ in a Vertical Wall Oriented South $\left(\mu=6.6^{\circ}\right)$, and $\varphi^{\prime}=\varphi$

In this special case, $\mathrm{O}=\mathrm{O}^{\prime}$. The delays are exactly the same along the year: all the curves are identical, except for their extreme points, as stated in Tale 3 (Fig. 13).

Minimum values for delays are 0 min every day at noon. Maximum values are for sunrise and sunset, and can reach $17.7 \mathrm{~min}$. Almost negligible advances correspond to solar hours near noon between 12.1 and 12.3 (not shown in Table 4).

New Gnomon Placed on $O$ in a Vertical Plane Perpendicular to the wall $(\mu=0)$, with $\varphi^{\prime}$ Different from $\varphi$

Results will depend on $\varphi^{\prime}$ but, in any case, no additional precision is obtained. Fig 14 shows, for example, $\varphi^{\prime}=40^{\circ}$.

New Gnomon Placed on $O$ in a Vertical Wall Oriented South $\left(\mu=6.6^{\circ}\right)$, with $\varphi^{\prime}$ Different from $\varphi$

As in the previous case, a slight variation of $\varphi^{\prime}$ causes a great distortion in the curves. Fig 15 shows, for example, for $\varphi^{\prime}=40^{\circ}$. 


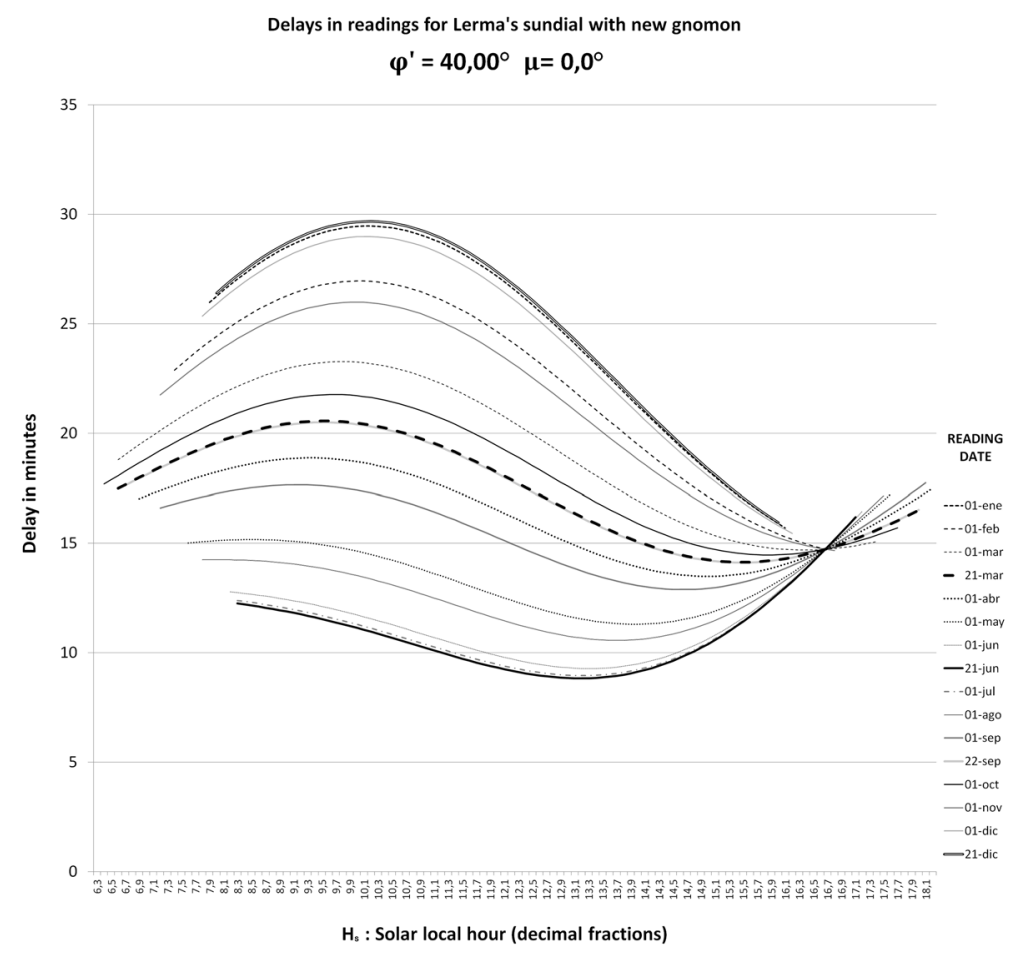

Fig. 14 Delays in readings for Lerma's sundial. $\varphi^{\prime}=40.00^{\circ}, \boldsymbol{\mu}=0.0^{\circ}$

\section{Other Combinations of $\mu$ and $\varphi^{\prime}$}

Different combinations have been checked and it is not worth showing all the functions in this paper. No additional precision is added, and the distributions of values seem almost random. The worst choices are those in which $\varphi^{\prime}$ differs from $\varphi$, which causes notables asymmetries in the functions. Other orientations can be dismissed, including intermediate positions between those analysed in "New Gnomon Located on O in a Vertical Plane Perpendicular to the Wall $(\boldsymbol{\mu}=0)$, with $\varphi^{\prime}=\varphi$ " and "New Gnomon Placed on $\mathrm{O}$ in a Vertical Wall Oriented South $\left(\boldsymbol{\mu}=6.6^{\circ}\right)$, and $\varphi^{\prime}=\varphi^{\prime}$, that is, values for $\varphi=\varphi^{\prime}$, with $\mu \neq 0^{\circ}$. The most suitable possibilities are, therefore, those shown in "New Gnomon Located on $\mathrm{O}$ in a Vertical Plane Perpendicular to the Wall $(\boldsymbol{\mu}=0)$, with $\varphi^{\prime}=\varphi$ " and "New Gnomon Placed on $\mathrm{O}$ in a Vertical Wall Oriented South $\left(\boldsymbol{\mu}=6.6^{\circ}\right)$, and $\varphi^{\prime}=\varphi^{\prime}$.

\section{Extrapolation to Sundials with Marks According to Incorrect Latitudes}

Considering that in the past templates or pre-calculated tables were widely used to simplify the engraving of the marks on sundials, and that these templates were usually made for integer values of latitude, frequent errors due to faulty latitudes can 


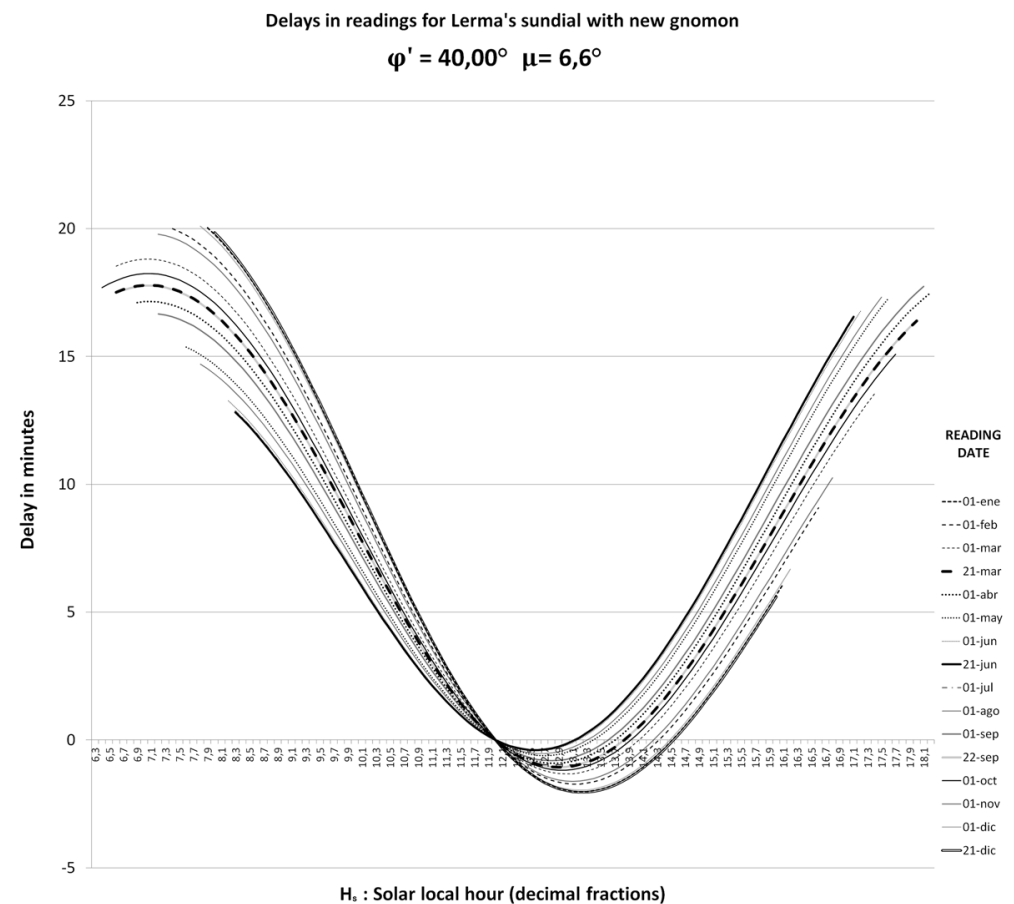

Fig. 15 Delays in readings for Lerma's sundial. $\varphi^{\prime}=42.03^{\circ}, \mu=6.6^{\circ}$

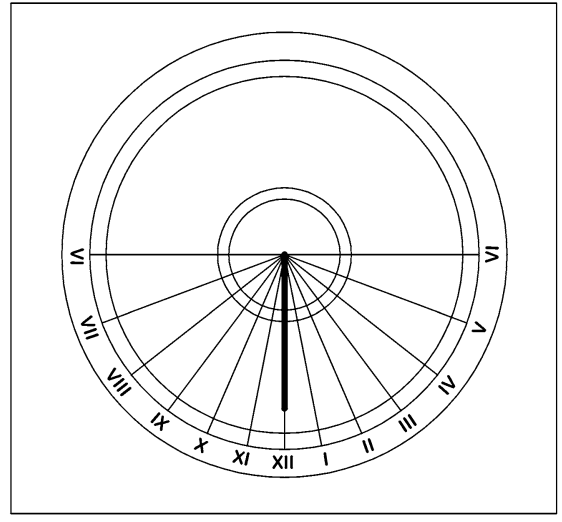

GNOMON PERPENDICULAR TO DIAL

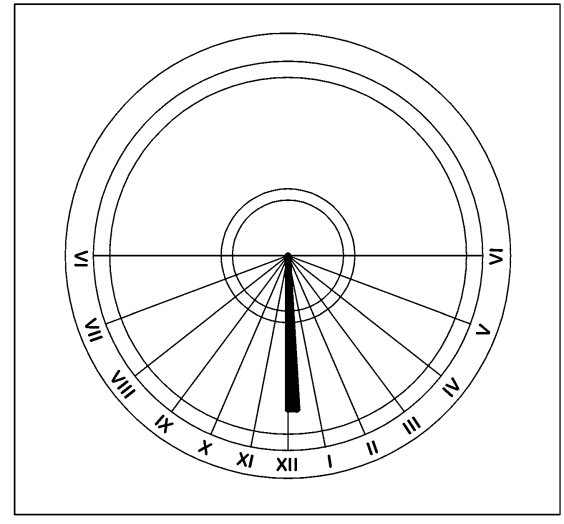

GNOMON ROTATED $6.6^{\circ}$

FRONTAL VIEWS

Fig. 16 The best choices for the sundial's restoration: graphical comparison between gnomon perpendicular to the dial and rotated gnomon (frontal views) 
be found in ancient sundials. Although Lerma's dial has no significant errors in latitude $\left(42^{\circ}\right.$ vs. $\left.42.03^{\circ}\right)$, the method developed to check possible orientations and geometrical features of a new gnomon can be used for the calculation of errors in sundials with marks corresponding to incorrect latitudes. In these cases, the procedure is similar to those followed in "New Gnomon Placed on O in a Vertical Plane Perpendicular to the wall $(\boldsymbol{\mu}=0)$, with $\varphi^{\prime}$ Different from $\varphi$ " or "New Gnomon Placed on $\mathrm{O}$ in a Vertical Wall Oriented South $\left(\boldsymbol{\mu}=6.6^{\circ}\right)$, with $\varphi^{\prime}$ Different from $\varphi$ ", with $\varphi$ being the correct latitude of the dial and $\varphi^{\prime}$ the wrong latitude corresponding to the marks. Angle $\mu$ will be different from 0 when the wall is also rotated.

For example, if we want to study a sundial whose marks correspond to a perfect South orientation ${ }^{6}$ for $43^{\circ}$ and the location of our dial is at $43.42^{\circ}$, with a real declination of $3.5^{\circ}$ East and with its gnomon located on a plane perpendicular to the wall (this last feature is usual in dials with marks facing South, despite their true orientations), the input datas will be

$$
\varphi=43.42^{\circ} \quad \varphi=43.00^{\circ} \quad \mu=0^{\circ} \quad \delta_{W}=3.5^{\circ}
$$

Of course, a preliminary study of the hours when the dial receives sunbeams will have to be performed to prevent obtaining nonsensical results, following the procedure explained in "Time Intervals in which the Dial is Operational".

\section{Conclusions}

For Lerma's sundial, results calculated at "New Gnomon Located on O in a Vertical Plane Perpendicular to the Wall $(\boldsymbol{\mu}=0)$, with $\varphi^{\prime}=\varphi$ " and "New Gnomon Placed on $\mathrm{O}$ in a Vertical Wall Oriented South $\left(\boldsymbol{\mu}=6.6^{\circ}\right)$, and $\varphi^{\prime}=\varphi$ " have different implications. The absence of errors at noon for the South-oriented gnomon, such as that studied in "New Gnomon Placed on $\mathrm{O}$ in a Vertical Wall Oriented South $\left(\boldsymbol{\mu}=6.6^{\circ}\right)$, and $\varphi^{\prime}=\varphi$ ", is not a negligible question in our case of study: the building which houses the dial is a church, and solar noon, was traditionally taken as a reference to ring the bell for the Angelus. Further, a constant distribution of errors throughout the year provides good grounds for choosing this option from a strictly mathematical point of view. The errors of choice shown in "New Gnomon Located on $\mathrm{O}$ in a Vertical Plane Perpendicular to the Wall $(\boldsymbol{\mu}=0)$, with $\varphi^{\prime}=\varphi$ " can reach more than $26 \mathrm{~min}$ in the days close to the winter solstice related to noon, and daily precision varies continuously. However, two facts must be taken into account. The first one is an aesthetic objection: the odd combination of a dial with symmetrical hours topped with a rotated gnomon can look bizarre, although the front view (Fig. 16) does not seem too striking.

The second objection is that purists of Lerma's history may prefer the presumably original gnomon. Let's bear in mind that an obsessive architectonic symmetry governs all the religious and civil historic buildings in Lerma; whether

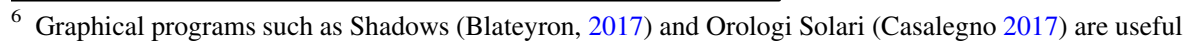
again for this analysis.
} 
this was the reason for the symmetric marks, or simply that the sundial's makers used a template neglecting the wall declination, we'll never know.

From a general point of view, the analysis of Lerma's sundial has helped us to fully elaborate an unusual procedure of calculation, since the existing treatises relative to gnomonics very often refer to the construction of new sundials, not to restoration. It has also been proved that the minimum errors for sundials with incorrect marks are associated with the better oriented gnomon, facing South. This was somewhat predictable, but we have numerically quantified these errors. And with the help of this study, we are now able to calculate reading errors in all vertical (non-inclined) sundials. We hope that this paper encourages sundial experts and enthusiasts to experiment with new proposals of restoration. In any case, and in our opinion, predictive tabulation of errors always ought to be a fact to be remarked prior to any restoration project.

Acknowledgements We want to thank Patricia Gallego Fernández de Aránguiz for her support at Lerma. All images are by the authors.

\section{References}

Blanco-Muriel, M., Alarcon-Padilla, D.C., Lopez-Moratalla,T. and Lara-Coira, M. 2001. Computing the solar vector. Solar Energy, 70(5):431-41.

Blateyron, F. 2017. Shadows 4.1. https://www.shadowspro.com/download/shadows.exe, accessed 9 September 2017

Casalegno, G. 2017. Orologi Solari. http://orologi-solari-le.software.informer.com/download/, Accessed 18 July 2017

Cervera Vera, L. 1981. La iglesia colegial de San Pedro en Lerma. Valladolid, Spain: Caja de Ahorros Municipal de Burgos.

Duffie J.A. and Beckman W.A. 2013. Solar Engineering of Thermal Processes. New York: John Wiley \& Sons.

Meeus, J. 1998. Astronomical Algorithms. Richmond, VA: Willman-Bell Inc.

NOAA. 2017. National Oceanic \& Atmospheric Administration. NOAA Solar Calculator. https://www. esrl.noaa.gov/gmd/grad/solcalc/calcdetails.html, accessed July 15, 2017.

Oglesby, M. 2004. A Design and Construction Manual for Flat Vertical Sundial Which Show Hours to Sunset (Italian Hours Labeled in Countdown Fashion). http://www.mysundial.ca/files/ H2SSManual040801.pdf, accessed 28 September 2017.

[SIGPAC] Sistema de Información Geográfica de parcelas agrícolas . Fondo Español de Garantía Agraria (FEGA). https://www.fega.es/es/PwfGcp/es/ayudas_dir_desa_rural/aplicacion_sigpac/index.jsp, accessed August 15, 2017.

Soler Gayá, R. 1997. Diseño y construcción de relojes de sol y de Luna. Palma de Mallorca, Spain: Colegio de Ingenieros de Caminos, Canales y Puertos. Demarcación Baleares.

Sproul, A. 2007. Derivation of the solar geometric relationships using vector analysis. Renewable Energy 32 (2007): 1187-1205.

Sun Earth Tools.(s.f.) http://www.sunearthtools.com/dp/tools/pos_sun.php?lang=es, accessed 30 July 2017.

U.S. Naval Observatory. 2005. Multiyear Interactive Computer Almanac 1800-2050. Washington DC: Willmann-Bell Inc.

Waugh, A. 1973. Sundials: Their Theory and Construction. New York: Dover Publications. 
Martín Perea-Álvarez de Eulate MSCE Civil Engineer (Universidad Politécnica de Madrid, Spain), has held senior positions in major Spanish construction firms and has also worked as a professor of Management in the Universidad Europea de Madrid and as a private consultant. He has completed his doctorate thesis in the University of Córdoba (Spain), related to the application of flat geometry and dihedral system to calculate the Sun's position. He has lectured and published papers on geometry and sunlight and has been reviewer for the journal Solar Energy (ed. Elsevier). Research interests: engineering, architecture, geometry, alternative procedures applied to astronomy education, solar energy and sundials.

Gloria Del Río-Cidoncha is Architect and PhD in Industrial Engineering from the University of Seville, where she is currently an associate professor of several subjects related to computer assisted design. She has been accumulating experience in developing educational software for engineering teaching, over the last years has published papers, and works on those subjects. Her major field of research is interactive multimedia systems, specifically innovative ways to teach engineering concepts with multimedia software and to improve spatial perception. Her research interest focuses on computer-aided design, industrial archaeology, architectural heritage and history of technology.

Francisco Montes-Tubío, Ph.D in Agricultural Engineering works currently as professor of the department of Graphic and Geomatic Engineering in the University of Córdoba (ETS de Ingenieros Agrónomos y de Montes). He has directed the Inter-university Master's Program on Representation and Design in Engineering and Architecture from 2011 until 2016 with the support of the universities of Córdoba, Málaga and Almería. He lectures the subjects of Engineering Drawing, Research on Agricultural Industrial Heritage, Aesthetics of Agricultural Industries and conducts the subject area of Geometrical Principles of Science and Technology in the Master Representation and Design in Engineering and Architecture and the course of Projects and Design of Olive mills within the Master Olivicultura and Elaiotecnia (University of Córdoba). Director of 50 doctoral theses and numerous final master projects connected with geometry and new technologies applied to virtual representation of heritage. 